\title{
Harvest Strategy Evaluation for School and Gummy Shark
}

\author{
André E. Punt and Fred Pribac \\ CSIRO Marine Research, GPO Box 1538, Hobart, TAS 7001, Australia \\ Bruce L. Taylor and Terence I. Walker \\ Marine and Freshwater Research Institute, Department of Primary Industries \\ Box 114, Queenscliff, VIC 3225, Australia
}

Punt, A. E., F. Pribac, B. L. Taylor, and T. I. Walker. 2005. Harvest Strategy Evaluation for School and Gummy Shark . J. Northw. Atl. Fish. Sci., 35: 387-406. doi:10.2960/J.v35.m517

\begin{abstract}
The Management Strategy Evaluation (MSE) approach is used to assess the benefits of alternative harvest strategies to set annual Total Allowable Catches (TACs) for school shark (Galeorhinus galeus) and gummy shark (Mustelus antarcticus). The harvest strategies are based on a stock assessment method that includes consideration of the gear-types employed in the fishery and the nature of the shark pupping process. The harvest strategies are compared in terms of performance measures that relate to average catches, catch variability and resource conservation. The uncertainties that impact performance to the greatest extent are the technical interaction between fishing for school shark and for gummy shark, the productivity of the overexploited school shark resource, and the extent to which tagged animals lose tags (or die) immediately after tagging.
\end{abstract}

Key words: Australia, gummy shark, harvest strategy, Monte Carlo simulation, school shark

\section{Introduction}

School shark (Galeorhinus galeus) and gummy shark (Mustelus antarcticus) form the major part of Australia's Southern Shark Fishery. Since 1 January 2001, this fishery has been managed by the Australian Fisheries Management Authority (AFMA) using output controls in the form of Total Allowable Catches (TACs) implemented as Individual Transferable Quotas (ITQs). The main gear-types employed in this fishery are baited longlines and monofilament gill-nets (presently 6-inch and 6.5-inch mesh), although small amounts of school and gummy shark are also taken using bottom trawl and other gear-types (Walker, 1999). The fishery is therefore unusual in that most of the shark catch is a result of targeted fishing rather than being by-product in fisheries for other species.

Gummy shark are assessed to be close to target levels at present whereas school shark are considered to be overexploited (McLoughlin et al., 2000). This difference in exploitation levels is attributable to several factors including differences in life history strategy; gummy shark are shorter-lived, mature earlier and produce more young. Although it is possible to target individual species at specific times and in specific places, fishery catches usually include both species. For example, in the past, up to $60 \%$ of the catch of school shark in Bass Strait was the result of targeted fishing rather than being an incidental catch when fishing for gummy shark (B. L. Taylor, pers. obs.). The aim of the management system is currently to promote the recovery of school shark without impacting unduly on the catches of gummy shark (McLoughlin et al. 2000). The catches of school shark need to be reduced to achieve this aim. However, reduced school shark TACs may lead to discarding of school shark if the level of incidental catch while for fishing for gummy shark leads to a catch in excess of the TAC.

There is widespread agreement in Australia (Smith et al., 1999; Punt et al., 2001a) and elsewhere (Butterworth et al., 1997) that the tactical decisions related to fisheries management (e.g. the setting of annual TACs) should be based on pre-specified harvest strategies ${ }^{\mathrm{a}}$. In this process, the decision-makers need to focus primarily on strategic issues such as the selection of operational management objectives and harvest strategies. A harvest strategy is a set of rules that defines the data to be collected from a fishery, how those data are to be analysed, and how the results of the data analyses are to be used to determine management actions. A key feature of the Management (or Harvest) Strategy Evaluation approach to fisheries management

a The term 'harvest strategy' is used throughout this paper due, primarily, to its use in Australia. The terms 'decision rule' (e.g. Starr et al., 1997) and 'management procedure' (Butterworth and Punt, 1999) have been used elsewhere for the same concept. 
(Smith, 1994; Punt et al., 2001a; Butterworth et al., 1997) is that candidate harvest strategies are compared using computer simulation in terms of their ability to satisfy the objectives for management and their robustness to uncertainty. The use of harvest strategies is therefore consistent with the precautionary approach to fisheries management (FAO, 1995).

There are five legislative objectives for the fisheries managed by the Australian Government (Anon, 1998). Two of these objectives - Ecological Sustainable Development (ESD) and Economic Efficiency - relate directly to dayto-day management of fisheries. The second of these objectives is not considered explicitly in the present study because it has been argued (Kaufmann et al., 1999) that it will be satisfied if, through quota trading, the fishery moves over time to a situation in which the catch is taken with a minimum of inputs. Allowing quota shares to be transferable allows the most efficient operators to obtain the greatest shares of the TAC. The ESD objective is extremely broad and includes consideration of inter alia the impact of fishing gear on non-target as well as target species. In the context of this study, however, performance relative to this objective is restricted to issues related solely to school and gummy shark.

Selection of a harvest strategy for a fishery requires not only technical input from scientists, but input from fishers on their likely reaction to changed management arrangements, and from the decision makers on their preferences for features to include in harvest strategies (such as minimum and maximum levels of TACs and maximum percentage changes in TACs). Management of fisheries in Australia involves broad participation at all levels by the key stakeholders (fishers, scientists, managers and members of conservation groups) (Smith et al., 1999). Several of the assumptions made during the development of the models, which underlie the calculations of the present study, were guided by the Southern Shark Fishery Assessment Group (SharkFAG). Issues of policy (e.g. guidelines on operational management objectives) were provided by the Shark Fishery Management Advisory Committee (SharkMAC) and the Australian Fisheries Management Authority (AFMA).

This paper compares candidate harvest strategies for school and gummy sharks in terms of their performance relative to operational definitions for the ESD objective. The harvest strategies all involve two components. The estimator (or stock assessment method) is used to analyze the data collected from the fishery to estimate the key quantities of interest to management (e.g. current biomass, maximum sustainable yield) as well as those quantities needed for TAC setting. The catch control law takes the results of the assessment (usually the current biomass) and determines the TAC from this. Only harvest strategies, based on the age-structured production model (ASPM) approach to fisheries stock assessment (Punt, 1994; Walker, 1994a,b), are considered in this paper. Although the assessment model used when applying ASPM is age-structured, it is not necessary to have data on the age-structure of the catch to fit this model. In contrast, it will be impossible to apply techniques such as Virtual Population Analysis (Pope and Shepherd, 1985) and Integrated Analysis (Methot, 1989, 1990) to school and gummy shark in the short- to medium-term. This is because these methods required data on the age-structure of the catch and there is presently a lack of ageing data for school and gummy shark. Harvest strategies based on simpler stock assessment methods (such as production models) perform more poorly than those based on the ASPM approach (A. E. Punt, unpubl. data) and so such harvest strategies are not examined in this paper.

\section{Materials and Methods}

The conceptual basis and rationale for the approach used to compare the performances of alternative harvest strategies has been described elsewhere (e.g. Southward, 1968; Hilborn, 1979; Donovan, 1989; McAllister et al., 1999; Smith et al., 1999; Punt et al., 2001a). Briefly, there are five steps in identifying the advantages and disadvantages of different harvest strategies (Fig. 1):

1) Identification of the management objectives and representation of these using a set of quantitative performance measures.

2) Identification of the alternative harvest strategies.

3) Development and parameterization of a set of alternative structural models (called operating models) of the system under consideration.

4) Simulation of the future use of each harvest strategy to manage the system (as represented by each operating model). For each year of the projection period (usually 15-25 years, 25 years in the case of this study), the simulations involve the following four sub-steps;

a) Generation of the types of data available for assessment purposes,

b) Application of a method of stock assessment to the generated data set to determine key managementrelated quantities and the inputs to the 'catch control law',

c) Application of the catch control law element of the harvest strategy to determine the TAC based on the results of the stock assessment, and 


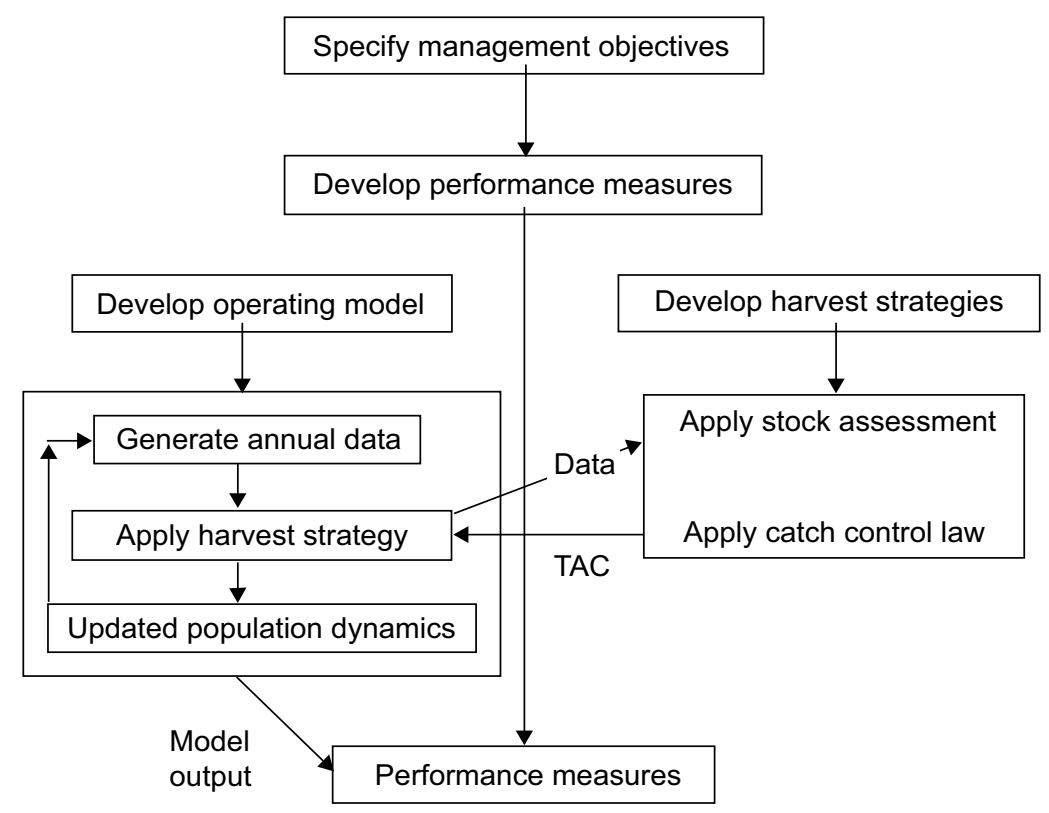

Fig. 1. Outline of the MSE approach.

d) Determination of the (biological) implications of this TAC by setting the catch for the 'true' population represented in the operating model based on the TAC.

5) Summarization of the results of the simulations (100 simulations for each scenario) by means of the performance measures and presentation of the results to the decision makers.

The following sections outline how the management objectives have been quantified; the details of the operating model, how future data are generated, and the alternative harvest strategies for the school and gummy shark fishery.

\section{Performance measures}

The following 15 performance measures were selected to compare candidate harvest strategies (each measure is computed separately for school and gummy shark unless indicated otherwise).

a) The lower $5^{\text {th }}$ percentile of the distribution of the average annual catch during 2000-24.

b) The median of the distribution of the average annual catch during 2000-24.

c) The upper $95^{\text {th }}$ percentile of the distribution of the average annual catch during 2000-24.

d) The median of the distribution for the average absolute variation in catch expressed as a percentage, $\% A A V$ :

$$
\% A A V=100 \sum_{t=2000}^{2024}\left|C_{t}-C_{t-1}\right| / \sum_{t=2000}^{2024} C_{t}
$$

where $C_{t}$ is the catch during year $t$.

e) The median of the distribution for the number of pups produced (all stocks combined) at the end of the projection period (2024) as a fraction of the virgin level (abbreviation 'Med $P_{f i n}$ ').

f) The probability that the number of pups produced in 2024 exceeds that in 1996 (abbreviation $\left.P\left(P_{2024}>P_{1996}\right)\right)$ (school shark only).

g) The median of the distribution of the ratio of the number of pups produced in 2024 relative to that in 1996 (abbreviation med $\left(P_{2024} / P_{1996}\right)$ ) (school shark only).

h) The probability that the number of pups produced in 2024 exceeds the lower of $40 \%$ of the virgin level and the 1994 level (abbreviation $P_{2024}$ ) (gummy shark only).

i) The median of the distribution for the fraction of the total catch that is discarded.

These 15 performance measures capture the key aspects of catch (measures a)-c)), catch variability 
(statistic d)) and resource conservation (statistics e)-i). The lower $5^{\text {th }}$ percentile of the average catch distribution can be considered to reflect the 'guaranteed catch'. These measures were chosen based on comments from SharkMAC and AFMA, agreed management reference points for the fishery, and the performance measures used in previous evaluations of harvest strategies. The choice of the 1996 pup production for school shark and the 1994 pup production and $40 \%$ of the virgin level for gummy shark are based on agreed short- and long-term management objectives for the fishery (Walker et al., 1998).

\section{The operating model}

The operating model consists of a biological component and a fishery component. In the interests of brevity, the full technical details of the operating model are not provided here. Rather, the following sections overview some of the key features of the operating model; the interested reader can consult Punt et al. (2001b) for the full mathematical specifications for the operating model.

The biological component of the operating model. The specifications for the current (1999) status, productivity and population dynamics of school and gummy shark are based on the assessments undertaken by Punt et al. (2000) and Punt et al. (2001b). Each operating model therefore involves specifications for certain of its aspects (e.g. the value assumed for natural mortality) with the remaining parameters estimated by fitting the operating model to the actual data for school and gummy shark. The operating models consider a wider range of scenarios than would be implied by conventional stock assessments. Scenarios that are not strongly supported by the assessments, such as low and high values for the maximum sustainable yield rate $\left(M S Y R^{\mathrm{b}}\right)$ (see Table 1$)$, are nevertheless examined when comparing harvest strategies to better assess the robustness of candidate harvest strategies to uncertainty. One reason for doing this is the common problem of under-estimating the true extent of uncertainty when carrying out fishery stock assessments (Ludwig et al., 1993; Punt and Butterworth, 1993; Walters and Pearse, 1996; Punt and Kennedy, 1997).

The school and gummy shark operating-models are spatially structured. The school shark operating-model considers eight regions (Fig. 2) whereas the gummy sharkoperating model considers three regions (South Australia, Bass Strait and Tasmania). Separate stocks of gummy shark are assumed to occur in each of the three gummy shark regions, whereas two stocks of school shark that mix are assumed to occur off southern Australia. These assumptions are consistent with those on which stock assessments of school and gummy shark are based (Punt et al., 2000; Pribac et al., 2004). Few data are available for the gummy shark population off Tasmania (Punt et al., 2001b; Pribac et al., 2004) so the values for the parameters for the gummy shark population off Tasmania are assumed to be the same as those for the gummy shark population in Bass Strait.

It is known from tagging data (e.g. Hurst et al., 1999) that school sharks in New Zealand waters move to Australia. The school shark model developed by Punt $e t$ al. (2000) therefore includes the possibly of movement of New Zealand school sharks to Australia. Movement from Australia to New Zealand is not included in previous assessments and hence not in the school shark operatingmodel because it is believed that the rate of fishing mortality in New Zealand is much lower than that in Australia. It is necessary to specify the (time-independent) ${ }^{\mathrm{c}}$ movement rate from New Zealand to Australia, the depletion of the New Zealand population in 1997, and the future level of fishing mortality in New Zealand for the scenarios that include movement from the stock of school shark in New Zealand to Australia. The base-case choice for the depletion of the New Zealand population (0.75) and the assumption that the harvest rate in New Zealand in future will be equal to the average for 1992-99 were selected by SharkFAG.

The status of the two species at the start of the projection period (2000) differs substantially. For the base-case scenario, the gummy shark population is close to $55 \%$ of its virgin level whereas the school shark population is $11 \%$ of this level. These specific percentages are sensitive to the specifications of the operating model but the qualitative impression of a highly depleted school shark resource and a gummy shark resource close to (or possibly above) conentional target levels is robust.

The fishery component of the operating model. The harvest strategies provide TACs for school and gummy shark for all of southern Australia. It is necessary therefore to specify how the TAC relates to the actual removals from the population by region and gear-type, and how different levels of TAC impact discarding practices. In principle, these effects depend on factors such as individual quota holdings, catch rates and investment strategies. However, there are currently no data upon which a model that

\footnotetext{
b MSYR is the ratio of MSY to $B_{M S Y}$.

${ }^{\mathrm{c}}$ Sensitivity tests (not shown here) indicate that the results are robust to some non-linearity in the relationship between the movement rate from New Zealand to Australia and the depletion of the New Zealand population.
} 
TABLE 1. The factors and levels considered in the biological component of the operating models (see Punt et al. (2001b) for the full technical details of these operating models). The levels indicated in bold typeface are part of the specifications for the base-case trial.

\begin{tabular}{cl}
\hline \hline Factor & Levels \\
\hline
\end{tabular}

\section{(a) Gummy shark}

Length-specific availability

Density-dependent component

MSYR

Initial depletion of pup production

(Bass Strait and South Australia)

Use 7-inch mesh gear data

Catch series

Ignore initial tag loss

\section{(b) School shark}

Movement rate from New Zealand $M S Y R$

Adult natural mortality, $M_{\text {adult }}$

Historical catches

Tagging contribution to the likelihood Depletion of the New Zealand stock Initial tag loss fraction
Estimated, uniform, constrained $>0.1$

Natural mortality, pup survival

Estimated, $11 \%, 15 \%, 25 \%$

Estimated, 0.5, 0.6, 0.7, 0.8

Yes, no

Base-case, alternative

No, yes

0\%, $2 \%, 5 \%, 7 \%, 10 \%$

Estimated, 3\%, 4\%, 5\%, 6\%, 7\%, 8\%, 10\%, 11\%, 12\%

$0.08 \mathrm{yr}^{-1}, \mathbf{0 . 1 \mathbf { y r } ^ { - 1 }}$

Base-case, alternative

Base-case, halved

$50 \%, \mathbf{7 5 \%}, 100 \%$

$\mathbf{2 0 \%}, 0,40 \%$

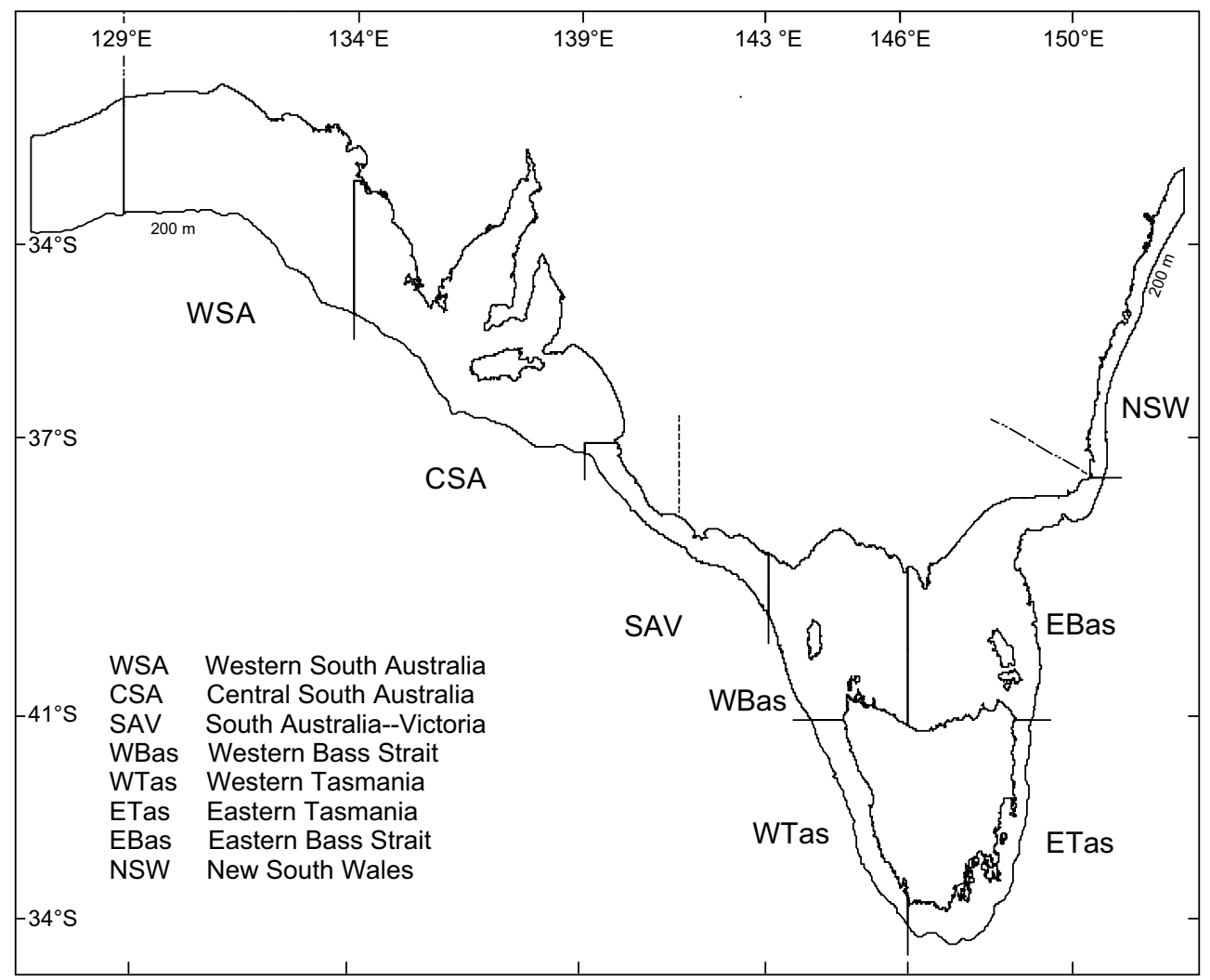

Fig. 2. Map of southern Australia showing the eight regions considered for school shark. 
includes these factors could be developed. Therefore, a simpler (and more empirical) approach based on the following three assumptions is used instead:

a) The split of the TAC to gear-type (within a region) is the same as it was in the last year for which actual data are available (1999).

b) The split of the TAC to region is determined by averaging the split to region for 1999 and the split which arises if the catch for Bass Strait (the historical centre of the fishery) remains at its average level over the last five years (if less than $95 \%$ of the TAC). The catches off Tasmania, South Australia and New South Wales are scaled to 'take up the slack'. The splits to regions are further modified by adding log-normal error with a coefficient of variation of 0.2 .

c) The maximum possible exploitation rate for gummy shark is based on the relationship between catch rate and abundance. This allows for gear competition (see Pribac et al. (2004) for details) while the maximum possible exploitation rate for school shark is assumed (semi-arbitrarily) to be 0.95 (in the absence of evidence for gear-competition).

There are several reasons for discarding in the Southern Shark Fishery. These include the impact of damage to the carcass (due, for example, to predation by sea lice, fish and marine mammals), high-grading and mismatches between the TACs for school and gummy shark. Discarding is therefore included in the operating model and all discarded sharks are assumed to die. The base-case extent of discarding due to damage and high-grading is assumed to be $5 \%$ as suggested by SharkFAG.

The discarding that results from mis-matches between the TACs for the two species is modeled by assuming that fishers modify their fishing practices to attempt to fully satisfy their TACs without over-catching (and hence discarding) either species. However, there are limits on the extent to which this is possible and, given some TAC mixes (in particular low school shark TACs and high gummy shark TACs) and the desire to fully catch the TACs for both species discarding is therefore inevitable even given the best intentions. The extent of discarding has been modeled by placing constraints on the ratio of the gummy shark to the school shark exploitation rate (by region). If the value for this ratio fails to satisfy these constraints when catches are set to the TACs, the catch of one species is increased until the ratio of the exploitation rates falls within the pre-specified constraints. This formulation mimics fishers targeting the species that is not fully caught, leading to discarding of the "constraining" species (usually school shark). The constraints on the ratio of the exploitation rates for the base-case trial are set to the extremes observed over the period 1994-97 (the "default" constraints) and sensitivity to alternative bounds (including no bounds whatsoever; i.e. perfect targeting by fishers) is examined during the tests of sensitivity.

\section{Future data collection}

The information that could be used by harvest strategies includes landed catches, catch rates, survey indices of relative abundance, length-frequency (by sex), age-composition (by sex), and tagging data (by sex). The landed catch for a given future year and region is calculated within the operating model as the lower of the total catch for that year and region and the component of the TAC for that year assigned to that region. The total catch may be less than the TAC if the fishing mortality corresponding to the TAC is equal to the maximum possible fishing mortality so that it is not possible to take the entire TAC. No estimates of discards are provided to the harvest strategies, which base their assessments on the landed catches because there is currently no program to estimate discards. Also, no future tagging or agecomposition data are generated by the operating model because there are no plans to collect these data on a regular basis in the future. The future catch-rate data are not used by the 'reference' harvest strategy considered in this study. When used, these data are assumed log-normally distributed about the model-predicted catch rate, with a non-linear relationship between catch-rate and abundance for gummy shark (Pribac et al., 2004). The data (catches, catch-rates, length-frequencies, etc.) for the years prior to the first application of the harvest strategy are taken to be the actual historical data.

The approach used to generate the survey estimates of relative abundance follows that used by Punt et al. (2001c). The survey estimates are generated assuming $N_{1}$ sites within the fishery are selected, these sites are sampled quarterly, and $N_{2}$ stations are sampled at each site each quarter. One survey site is assumed established in each of the WSA, CSA, ESA, WBas and WTas regions (Fig. 2 ) and two survey sites are assumed established in the EBas region (i.e. $N_{1}=7$ ). It is assumed that the survey provides an index of the component of the population available to 6.5 inch mesh gear off South Australia and Tasmania and available to 6 inch mesh gear in Bass Strait. There are two sources of measurement error associated with the surveys: the variability that arises from sampling the population in the area being surveyed, and the level of 'additional' variation due to fluctuations in catchability, e.g. in the fraction of the population present at the sites 
being surveyed. Sampling variability can be reduced by undertaking survey shots at additional stations at each site while 'additional' variability can only be reduced by sampling a large number of sites frequently. The coefficients of variation for the two sources of measurement error are denoted $\sigma_{s}$ and $\sigma_{A}$, respectively.

For this study, it is assumed that 'additional' variation is common to all stations at a survey site (but independent among sites and quarters). The survey index for region $r$ and year $t, l_{t}^{r, o b s}$, is defined as the average number of sharks caught per station during the survey, and is therefore given by:

$$
l_{t}^{r, o b s}=\frac{1}{4 N_{1}^{r} N_{2}} \sum_{z=1}^{N_{1}^{r}} \sum_{q=1}^{4} \sum_{s=1}^{N_{2}} l\left[\frac{\kappa}{B_{1998}^{r}} B_{t}^{r} e^{\varepsilon_{z, q, t}^{r}-\sigma_{A}^{2} / 2} e^{\eta_{z, q, s t}^{r}-\sigma s / 2}\right]
$$

where $B_{t}^{r} \quad$ is the biomass in region $r$ during year $t$ available to the size of gill-net used during the survey (1998 was the year in which a pilot fixed-station survey took place),

$N_{1}^{r} \quad$ is the number of sites in region $r$,

$I[\times]$ denotes the nearest integer to $x$,

$\kappa \quad$ is the average catch during the pilot survey (22.6 sharks per station for gummy shark and 2.0 for school shark - see Prince et al. (1999) for details on the pilot fixed-station survey),

$\varepsilon_{z, q, t}^{r} \quad$ is the error due to 'additional' variance when sampling site $z$ in region $r$ during quarter $q$ of year $t\left(\varepsilon_{z, q, t}^{r} \sim N\left(0 ; \sigma_{s}\right)\right)$, and

$\eta_{z, q, s, t}^{r} \quad$ is the sampling error corresponding to sampling station $s$ at site $z$ in region $r$ during quarter $q$ of year $t\left(\eta_{z, q, s, t}^{r} \sim N\left(0 ; \sigma_{s}\right)\right)$.
The survey index for year $t$ is therefore defined as the (arithmetic) average survey catch rate over all stations sampled during year $t$. The impact of variation among stations in shot duration is ignored as this is minor (Prince et. al., 1999). Changes in biomass over the year are also ignored. Table 2 lists the base-case values assumed for $N_{2}, \sigma_{A}$, and $\sigma_{\mathrm{s}}$. The values for $\sigma_{s}$ are based on an analysis of the data collected during the pilot survey (Prince et al., 1999). The value assumed for $\sigma_{A}$ is largely an educated guess. Sensitivity tests consider the implications of the actual values for these parameters differing from those assumed.

Length-frequency data are generated for only gummy shark for consistency with current assessment practice. The observed length-frequency data for a given region, sex and gear-type are a multinomial sample from the corresponding model-predicted catch length-frequency distribution. The base-case length-frequency sample sizes (for gummy shark), 1000 (Bass Strait) and 850 (South Australia), were determined using the approach developed by McAllister and Ianelli (1997).

\section{The harvest strategies}

Setting of global (i.e. southern Australia-wide) TACs for school and gummy shark involves several steps. These steps mimic the actual practice of setting TACs for the Southern Shark Fishery. First, stock assessments are conducted and initial TACs determined. These initial TACs are then modified to conform with rules on the maximum extent to which TACs may change from one year to the next and then rounded to the nearest 100 tons (gummy shark) and 25 tons (school shark). After this, any carryover of (uncaught) quota from the previous year is added to the TAC. The following sections outline each of the steps in more detail.

Stock assessments are undertaken and initial TACs calculated for only Bass Strait (WBas and EBas combined)

TABLE 2. The specifications for the generation of future data. The values indicated in bold typeface form part of the specifications for the base-case trial.

\begin{tabular}{lcc}
\hline \hline Model parameter & Value - school shark & Value - gummy shark \\
\hline Catch-rate data & & \\
$\quad$ Sampling error, $\sigma_{q}$ & $0.212, \mathbf{0 . 3}, 0.424$ & $0.212, \mathbf{0 . 3}, 0.424$ \\
Survey data & $3, \mathbf{6}, 12$ & $3, \mathbf{6}, 12$ \\
$\quad$ Stations per survey site, $N_{2}$ & $\mathbf{1 . 1 3 2}$ & $\mathbf{0 . 8 4 9}$ \\
Sampling error, $\sigma_{s}$ & $\mathbf{0 . 2}, 0.4$ & $\mathbf{0 . 2}, 0.4$ \\
Additional variance, $\sigma_{A}$ & & $0, \mathbf{1 0 0 0}$ \\
Length frequency sample size & $\mathbf{0}$ & $0, \mathbf{8 5 0}$ \\
Bass Strait & $\mathbf{0}$ & \\
South Australia & &
\end{tabular}


and South Australia (WSA and CSA combined) for consistency with past practice and because there are insufficient data to conduct reliable assessments for the Tasmanian and NSW regions. The global (i.e. southern Australia-wide) initial TACs for year $t$ are then determined by multiplying the sum of the initial TACs for Bass Strait and South Australia for year $t$ by the ratio of the global catch for year $t-1$ to the catch for year $t-1$ for Bass Strait and South Australia.

The TAC based on the harvest strategy is only changed once every $3^{\text {rd }}$ year as suggested by SharkMAC. The management arrangements for the Southern Shark Fishery permit $20 \%$ of the TAC to be carried over from one year to the next. The actual TAC for year $t+1, T A C_{t+1}^{a c t}$, is therefore determined from $T A C_{t}^{a c t}$, the TAC for year $t+1$ from the harvest strategy, $T A C_{t+1}$, and the landed catch for year $t, C_{t}$, using the formula:

$$
T A C_{t+1}^{\text {act }}=T A C_{t+1}+\min \left(T_{A C_{t}^{a c t}}-C_{t}, 0.2 T A C_{t}^{\text {act }}\right)
$$

This equation assumes that the maximum possible carryover of TAC occurs. This assumption is based on the observation in Australia's South East Trawl Fishery that operators lease uncaught quota in excess of the $20 \%$ maximum permissible carry-over to operators who have caught more than $80 \%$ of their allocation near the end of the year. The operators then lease the quota back at the start of the following year so as to maximise the amount of uncaught quota that can be carried-over (J. Prince, Biospherics Pty Ltd, pers. comm.).

There are several ways in which the ASPM method of stock assessment can be applied. The options considered in this study are:

a) estimate only $M S Y R$ and $B_{0}$,

b) estimate $M S Y R, M_{a d u l t}$ and $B_{0}$, and

c) estimate $M S Y R, M_{\text {adult }}, B_{0}$ and the recruitment residuals for the last 10 years of the assessment period.

The last variant is similar to the Integrated Analysis approach (Methot, 1989, 1990) as it attempts to identify the strong and weak year-classes. Only the last 10 recruitment residuals are estimated so as to keep the computation time requirements of the calculations within feasible limits. The values for the pre-specified parameters of the assessment model (such as growth rates, the selectivity pattern of the gear, etc.) are set equal to the base-case trial values, except that unestimated historical recruitment residuals are assumed to be zero. The historical (pre-2000) catches assumed when applying the harvest strategy are taken to be those corresponding to the base-case trial. Given the results from an ASPM assessment, the initial TAC for year $t$ is then computed using the following catch control law:

$$
T A C_{t}= \begin{cases}0 & \text { if } B_{t}^{\text {cur }}<B^{\text {thresh }} \\ F^{\text {targ }} B_{t}^{\text {cur }} & \text { if } B_{t}^{\text {cur }}<B^{\text {thresh }} \\ F^{\text {targ }} B_{t}^{\text {cur }}\left(B_{t}^{\text {cur }} / B^{\text {thresh }}\right) & \text { otherwise }\end{cases}
$$

where $T A C_{t}$ is the initial TAC for year $t$,

$F^{\text {targ }}$ is the 'target' exploitation rate,

$B^{\text {thresh }}$ is a threshold biomass below which the target exploitation rate is reduced linearly to zero, and

$B_{t}^{c u r}$ is an estimate of the biomass at the start of year $t$.

It is also possible to constrain the initial TAC to be less than the estimate of the Maximum Sustainable Yield, $M S Y$ (Butterworth, 1987). $F^{\text {targ }}$ is taken to be $\theta_{1} M S Y R$ and $B^{\text {thresh }}$ is taken to be $\theta_{2} B_{M S Y}$ for the purposes of this study. The values assumed for $\theta_{1}$ and $\theta_{2}$ can be selected to achieve different risk-reward trade-offs and to give greater (lesser) emphasis to recovery from over-exploitation.

\section{Results and Discussion}

Given the large potential volume of results, it is prudent to select a 'reference' harvest strategy to form the focus for the comparison of alternative harvest strategies. The 'reference' harvest strategy includes specifications related to the method of stock assessment, the catch control law, and the constraints imposed to reduce inter-annual variation in catches. The 'reference' harvest strategy is specified to achieve a 'reasonable' balance between resource conservation and utilization so that the sensitivity analyses can focus on an area of performance space that it not too far from that which the decision makers are likely to be interested in. The sensitivity of the results is then examined to changing some of the features of: (a) the 'reference' harvest strategy, (b) the biological component of the operating model, and (c) the data available for assessment purposes.

\section{Selection of a 'reference' harvest strategy}

A series of 25-year projections based on the basecase trial (Table 1) were undertaken (Table 3). The initial TAC from 2000 onwards for gummy shark in these projections was fixed at 1525 tons (the minimum suggested by SharkMAC) and the initial TAC from 2000 
TABLE 3. The probability of the number of school shark pups exceeding the 1996 level in 2024, the median annual catch of school shark during 2000-24, the median of the ratio of the number of pups in 2024 to that in 1996, and the percentage of the catch during 2000-24 that is discarded. Results are shown for a series of harvest strategies that pre-specify the annual (initial) TACs. The initial TAC for gummy shark is 1525 tons for all of the analyses in this Table.

\begin{tabular}{ccccc}
\hline \hline & \multicolumn{3}{c}{ Restrictions on annual reductions in TAC } \\
\cline { 2 - 5 } & $20 \%$ & $50 \%$ & None & $\begin{array}{c}\text { None } \\
\text { (no discarding) }\end{array}$ \\
& & & & \\
$P\left(P_{2024}>P_{1996}\right)$ & & & & \\
319 ton TAC & 0 & 0 & 0 & 0 \\
200 ton TAC & 0 & 12 & 17 & 100 \\
150 ton TAC & 1 & 52 & 67 & 100 \\
100 ton TAC & 2 & 99 & 100 & 100 \\
Median catch & & & & \\
319 ton TAC & 319 & 317 & 317 & 317 \\
200 ton TAC & 230 & 203 & 200 & 200 \\
150 ton TAC & 201 & 159 & 150 & 150 \\
100 ton TAC & 184 & 118 & 100 & 100 \\
$m e d\left(P_{2024} P_{1996}\right)$ & & & & \\
319 ton TAC & 38 & 42 & 42 & 43 \\
200 ton TAC & 81 & 94 & 95 & 122 \\
150 ton TAC & 87 & 101 & 103 & 155 \\
100 ton TAC & 90 & 111 & 115 & 189 \\
Fraction discarded & & & & \\
319 ton TAC & 5 & 5 & 5 & 5 \\
200 ton TAC & 11 & 20 & 21 & 5 \\
150 ton TAC & 18 & 35 & 39 & 5 \\
100 ton TAC & 23 & 49 & 56 & 5 \\
\hline
\end{tabular}

onwards for school shark was varied from 100 to 319 tons (319 tons was the minimum TAC originally identified by SharkMAC). Note that being initial (constant) TACs, they are subject to the rules regarding the maximum extent of change and carryover of uncaught quota. Results are shown in Table 3 for no restrictions on TAC changes (i.e. TACs can be reduced by $100 \%$ if this is considered necessary), a maximum percentage reduction of $20 \%$ (i.e. TACs can be reduced by $20 \%$ from one year to the next), and a maximum percentage reduction of $50 \%$. The results of the projections are summarized by $\left.P\left(P_{2024}>P_{1996}\right)\right)$, the median annual catch of school shark, med $\left(P_{2024} / P_{1996}\right)$, and the fraction of the total catch of school shark that is discarded.

As expected, lower initial TACs correspond to greater probabilities of the school shark pup production exceeding the 1996 level in 2024. However, the extent of discarding due to mismatches between the school and gummy shark TACs increases substantially as the level of initial TAC is reduced. The impact of this TAC-related discarding (i.e. mismatches between the TACs for school and gummy shark) can be assessed by comparing the two "none" columns in Table 3. For example, for a 100 tons annual initial TAC, the value of med $\left(P_{2024} / P_{1996}\right)$ is $189 \%$ when there is no TAC-related discarding but only $115 \%$ when there is such discarding. The discarded component of the catch is predicted to be larger than the retained component of the catch for an initial TAC from the year 2000 of 100 tons if no restrictions are placed on the extent to which TACs for school shark can be reduced. The impact of the restrictions on allowed changes in TACs can also be substantial. For example, the value of $P\left(P_{2024}>P_{1996}\right)$ for the 150 tons initial TAC scenario increases from $1 \%$ to $52 \%$ and then to $67 \%$ as the restrictions on TAC changes are weakened 
from $20 \%$ to $50 \%$ and then to none. It should be noted, however, that the landed catches are higher for the 50 and $20 \%$ restrictions than for no restrictions because it takes several years of $20 \%$ reductions in TAC to reach a TAC of (say) 100 tons given the 1999 catch was actually 450 tons.

None of the minimum TAC levels perform particularly well in terms of achieving stock recovery (i.e. a high value for med $\left.\left(P_{2024} / P_{1996}\right)\right)$ because of the impact of discarding. However, minimum TACs of 150 tons and 100 tons lead to a better-than-even chance of some recovery by 2024 . The remaining calculations of this paper are based on a minimum TAC of 150 tons.

The 'reference' harvest strategy includes the following specifications:

a) Only $B_{0}$ and $M S Y R$ are treated as estimable parameters when applying ASPM; the values for the remaining parameters are set to those for the base-case trial. The estimator uses all of the tagging, age-composition and lengthfrequency information, the historical catch-rate data and any future survey data (the surveys are assumed to start in 1998). It ignores any future commercial catch-rate data.

b) The initial TAC is bounded above by $M S Y$ for school shark. The value of $B^{\text {thresh }}$ is set to $0.5 B_{M S Y}$ so that the target level of fishing mortality is constant above $0.5 B_{M S Y}$ and declines linearly to zero below this. The initial TAC is set to zero if the expected number of pups is less than $5 \%$ of the virgin level.

To fully specify a 'reference' harvest strategy, it is necessary to choose values for $\theta_{1}$ for school and gummy shark, and whether the initial TAC for gummy shark is bounded above by the estimate of MSY. Table 4 therefore lists the values for the 15 performance measures for the base-case trial for nine harvest strategies constructed by making various choices for these three factors. Results are shown for two variants of the base-case trial related to the constraints on the exploitation rates for school and gummy shark. These are a) the default values (see the specification of the fishery component of the operating model for details), and b) none because it is assumed that fishing practices can be modified to avoid any TACrelated discarding (high-grading/additional damagerelated discarding at 5\% still occurs, however).

The results for gummy shark are largely insensitive to the constraints on the exploitation rates (contrast the results for gummy shark in Tables $4 a$ and $4 b$ ). This is because school shark rather than gummy shark is the 'limiting' species; the range of catches for gummy shark is such that TAC-related discarding of school shark is likely given the desire to allow some recovery of school shark without deliberately reducing the catches of gummy shark. The results for school shark are highly dependent on the constraints on the exploitation rates. For example, the probability of exceeding the 1996 pup production in 2024 is almost $100 \%$ for the harvest strategies in which $\theta_{1}$ for school shark is 0.4 or 0.7 when fishers are able to avoid school shark (Table 4b). However, this probability is no greater than $38 \%$ when fishers are unable to avoid school shark (Table 4a).

The results for gummy shark are insensitive to the value assumed for $\theta_{1}$ for gummy shark but substantially higher catches result when the initial TAC is not bounded by the estimate of $M S Y$. For school shark, the probability of being above the 1996 pup production in 2024 is greater if the target exploitation rate (determined by $\theta_{1}$ for school shark) is lower and if the initial TAC for gummy shark is bounded by the estimate of MSY.

The 'reference' harvest strategy for the remaining calculations of this paper is based on $\theta_{1}=0.7$ and 1 for school and gummy shark, respectively, while the initial TAC for gummy shark is not bounded by the estimate of MSY for gummy shark ( $2^{\text {nd }}$ last rows in Tables $4 \mathrm{a}$ and 4b). This particular harvest strategy variant was selected for further consideration because it achieves high catches of gummy shark ( $\sim 800$ tons per annum) and does not leave the school shark resource far below the 1996 level in 2024 if fishing practices remain essentially unchanged. It also achieves a high probability of recovering the school shark resource to above the 1996 level if fishing practices can be modified to avoid TAC-related discarding.

Figure 3 shows the time-trajectories of catch (landed and total) and TAC (as set by the harvest strategy and after adjustment for carryover) for the 'reference' harvest strategy for one simulation for the base-case trial. The TACs for school shark are always fully taken so no carryover of school shark TAC occurs (i.e. the results for "TAC" and "TAC (incl. Carryover)" in Fig. 3 are identical). In contrast, the impact of 'gear competition' means that the TACs for gummy shark are not fully taken so there is some carryover (see the right panels of Fig. 3). The level of discarding is small for gummy shark (Fig. 3 right panels). However, this is not the case for school shark when constraints are placed on the relative exploitation rate because the total catch of school shark can substantially exceed the landed catch of this species (Fig. 3 upper left panel). 
PUNT et al.: Harvest Strategy Evaluation

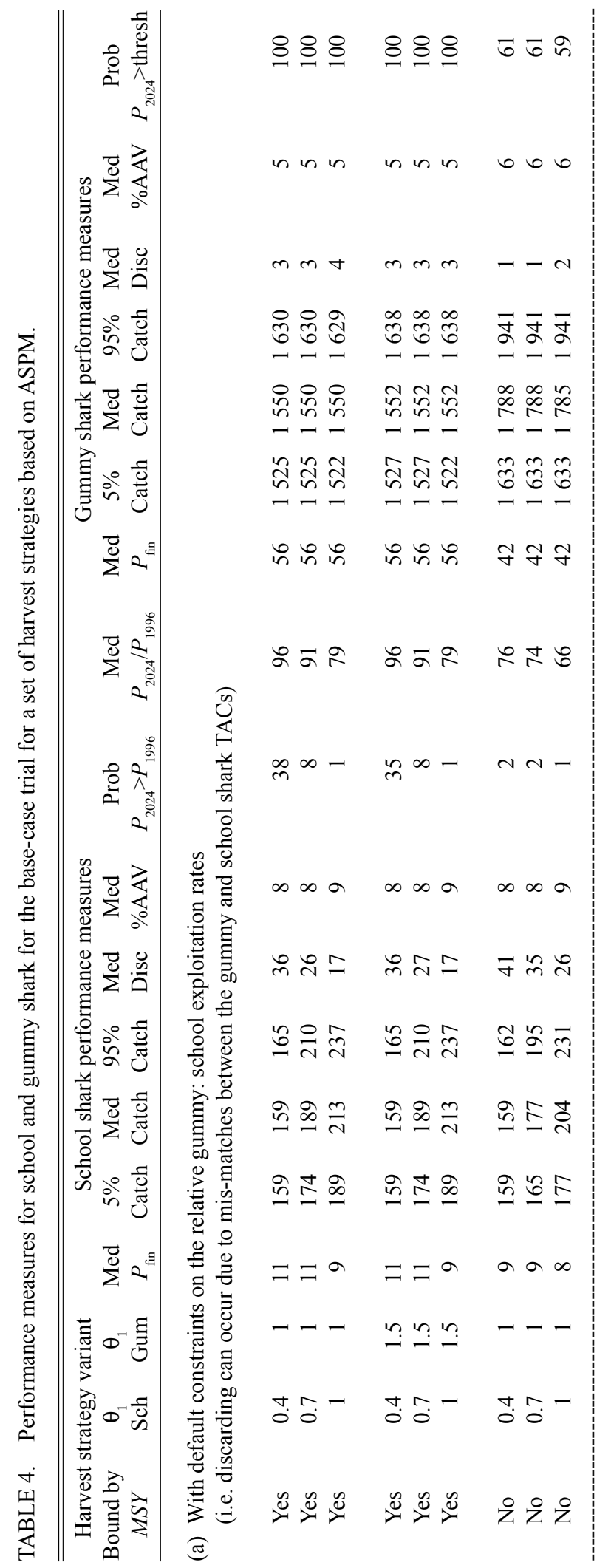

๕๐ㅇำ

nnin nin 606

(n)

men men $-\cdots$

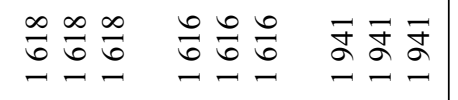

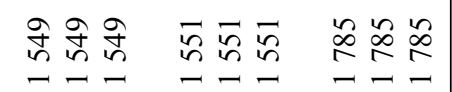

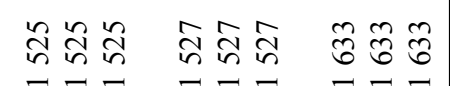

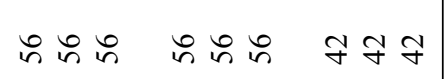

แn

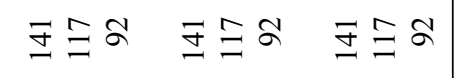

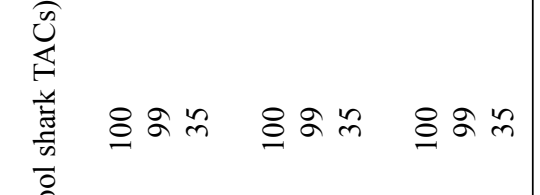

它

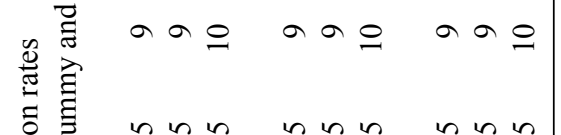

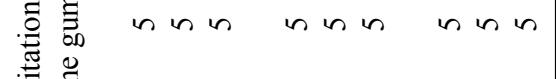

范

离卷

昜

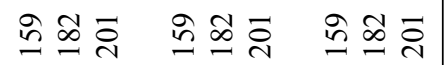

:

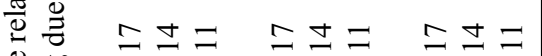

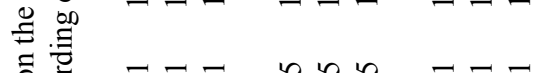

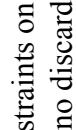

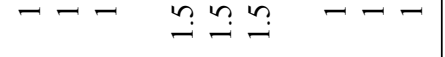

$\dot{0} \overrightarrow{0}-\overrightarrow{0} \dot{0}^{-}$

¿

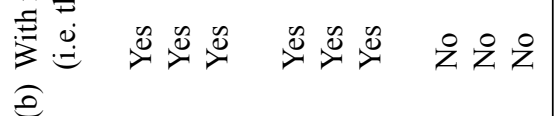



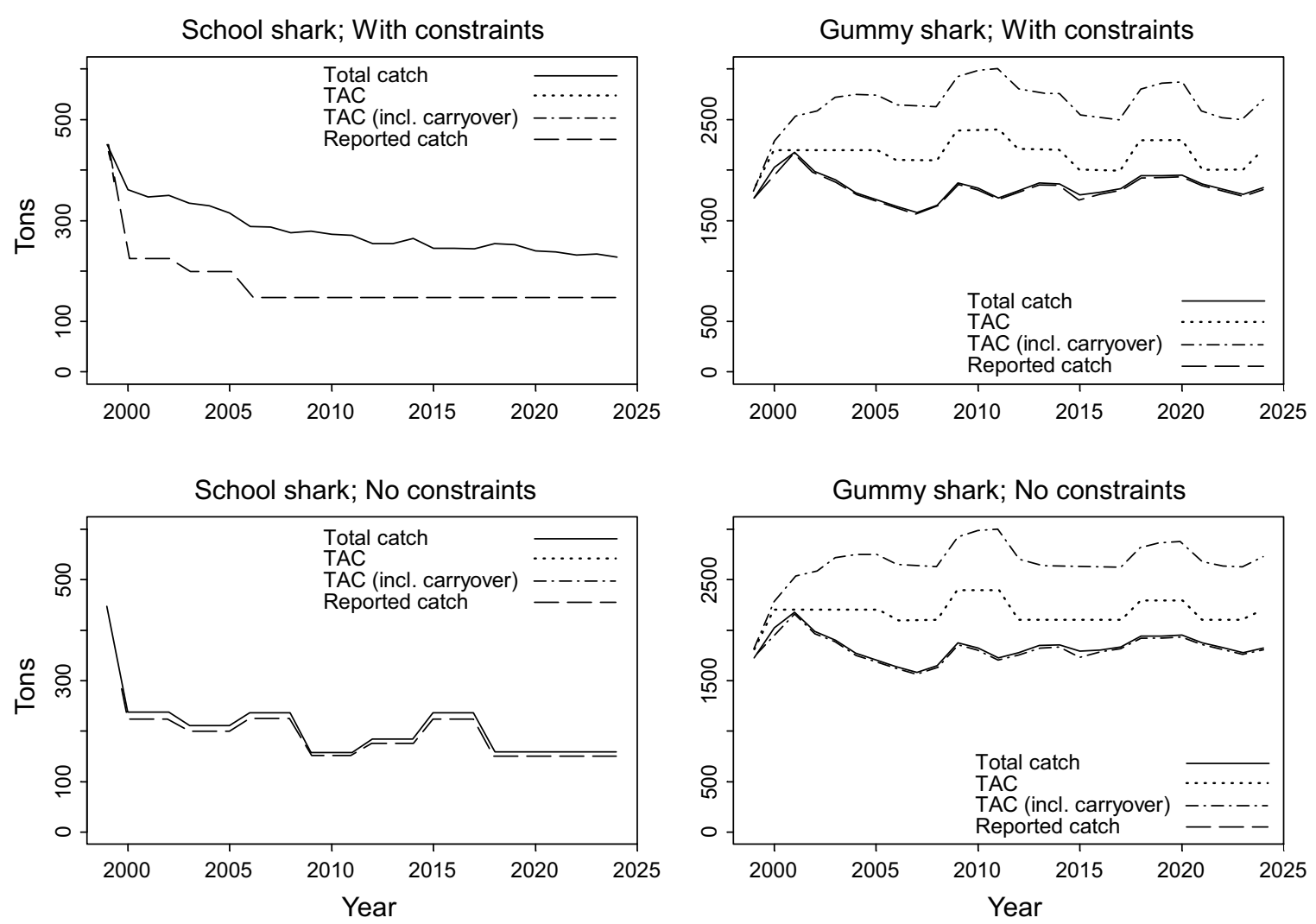

Fig. 3. Time-trajectories of the TAC set by the harvest strategy (the initial TAC modified by the constraints on the extent of change in TAC and rounding), the actual TAC allocated (accounts for any carryover), the total catch removed from the population and the catch reported for use in stock assessments (which differs from the total catch due to (un-reported) discards).

\section{Sensitivity to the harvest strategy}

Table 5 examines the performances of several additional variants of the 'reference' harvest strategy for the variant of the base-case trial in which the default constraints are placed on the relative gummy: school exploitation rates. Estimating the natural mortality rate, $M$, for gummy shark or the recruitment residuals for the last 10 years (rows "Estimate gummy $M$ " and "Estimate rec resids") has virtually no impact on the results for school shark. The median of the distribution for the average annual catch of gummy shark is higher when $M$ for gummy shark is estimated, but this distribution is also much wider so the 'guaranteed' average catch is actually no larger than is the case for the 'reference' harvest strategy. The median final depletion of the pup production for gummy shark is only $38 \%$ (the lowest value in Table 5 ) when $M$ for gummy shark is treated as an estimable parameter. Consequently, the probability of the gummy shark pup production being above the lower of $40 \%$ of the virgin level and the 1994 level $\left(P_{2024}>\right.$ thresh $)$ is only 0.41 compared with the 'reference' value of 0.61 .

Increasing the value of $\theta_{2}$ from 0.5 to 0.7 (row ' $\theta_{2}=0.7$ ' in Table 5) leads to lower average catches of school shark but has little impact on the probability of being above the 1996 pup production in 2024 because the extent of TAC-related discarding increases when $\theta_{2}=0.7$. Decreasing $\theta_{2}$ from 0.5 to 0.1 leads to the opposite effects. The results for gummy shark are not sensitive to the value assumed for $\theta_{2}$ because the gummy shark population is hardly ever reduced to levels at which this specification plays a role.

The results for school shark are insensitive to amount of carryover because the school shark TAC is always fully caught (Fig. 3). In contrast, ' $P_{2024}>$ thresh' for gummy shark is very sensitive to whether the extent of carryover is 10,20 (base-case) or $30 \%$. There is relatively little difference (20 tons) between the average annual catches 
for gummy shark for 10 and $20 \%$ carryover rates but ' $P_{2024}$ thresh' increases by $20 \%$ if the carryover is $10 \%$ rather than $20 \%$.

\section{Sensitivity to the form of the operating model}

Table 6 examines the sensitivity of the results for gummy shark to changing the specifications related to the gummy shark component of the operating model. Results are not shown for the case in which selectivity is assumed to be uniform because this case provides a very poor fit to the data. Table 6 focuses only on the results for gummy shark because the results for school shark are almost independent of the specifications of the gummy shark component of the operating model.

The ability to leave the number of gummy shark pups above the lower of $40 \$$ of the virgin level and the 1994 level is compromised if availability is more uniform than estimated by the base-case assessment (row 'Constrained availability' in Table 6). This ability can also be compromised if density-dependence acts on pup survival rather than on the natural mortality rate of all animals (row 'Density-dependent pups' in Table 6). The harvest strategy does 'learn' that productivity is over-estimated because average catches are lower for the 'Constrained availability' and 'Density-dependent pups' trials. The median average annual catches, median final depletion and ' $P_{2024}>$ thresh' all increase as MSYR is increased from 0.11 to 0.15 and then to 0.25 (Table 6). It is noteworthy, however, that the lower $5^{\text {th }}$ percentile for the average catch distribution is lower when $M S Y R=0.25$ than for the base-case trial. This presumably arises because, in some simulations with a high $M S Y R$, the population recovers before the estimator component of the harvest strategy is able to detect this. Poor performance of harvest strategies when $M S Y R$ is high has been observed in other cases (e.g. Punt and Butterworth, 1989).

Average catch, final depletion and ' $P_{2024}>$ thresh' all increase with the initial (2000) depletion of the resource, although whether this is due to the impact of initial depletion or MSYR (which is correlated with initial depletion) is unclear. More pessimistic results than those for the base-case operating model are obtained when the results for the operating model based on the alternative catch series (derived from hypotheses on the extent of historical under-reporting of catches). The results are particularly pessimistic when the length-frequency data for 7-inch mesh gear are ignored when estimating the parameters of the operating model (rows 'Alternative catches' and 'Ignore 7-inch mesh data' in Table 6). Ignoring the possibility of initial tag-loss/tagging mortality (i.e. setting the fraction of tagged animals that die or lose tags immediately after being tagged to zero when estimating the parameters of the operating model) leads to more optimistic results. Presumably this is because the initial depletion is estimated to be larger when initial tag-loss/ tagging mortality is ignored.

Table 7 and Fig. 4 examine the sensitivity of the results for school shark to changing the specifications related to the school shark component of the operating model. The most important sensitivity is to the value assumed for initial tag-loss / tagging mortality. Reducing initial tag-loss/tagging mortality to 0 (row "No initial tag-loss" in Table 7) implies that the 'reference' harvest strategy has a 0.46 probability of allowing recovery to the 1996 pup production by 2024. However, increasing this fraction to 0.6 leads to very pessimistic results (e.g. a median final depletion of only $3 \%$ of the pre-exploitation level). This sensitivity test also impacts performance for gummy shark in that the relatively high catches of school shark lead to some discarding of gummy shark (rather than the other way around). The performance for school shark becomes more optimistic when $M_{\text {adult }}$ is assumed to be $0.08 \mathrm{yr}^{-1}$ rather than $0.1 \mathrm{yr}^{-1}$, when the tagging data are downweighted, and when the catch series is replaced by an alternative series of catches that attempts to account for historical under-reporting (rows ' $M_{\text {adult }}=0.08 \mathrm{yr}^{-1}$, "Halve tag contribution" and "Alternative catches" in Table 7). The last result may seem initially surprising because the initial depletion is lower when the base-case catch series is replaced by the alternative series. However, this is more than compensated for by a larger estimated value for MSYR.

The results generally become more pessimistic when allowance is made for movement from New Zealand to Australia. The effect of this is greater for higher values for the movement rate (e.g. row ' $\mathrm{NZ}$ movement rate $=$ $10 \%$ ' in Table 7) and if the New Zealand population is more depleted.

As expected, the values for the performance measures for school shark are highly sensitive to the value assumed for $M S Y R$ (Fig. 4). For MSYR values $<4 \%$ ("no constraints") and $<6 \%$ ("with constraints"), there is a better than even chance that the number of pups in 2024 will be less than half of that in 1996 (Fig. 4; lower right panel). In contrast, the probability of being above the 1996 pup production in 2024 exceeds $80 \%$ for $M S Y R$ values of $9 \%$ and above for the "no constraints" case. The discard rate for the "with constraints" case increases with MSYR (Fig. 4). Although the performance of the harvest strategy depends on the true value of $M S Y R$, this is unfortunately a very difficult parameter to estimate; current assessments 


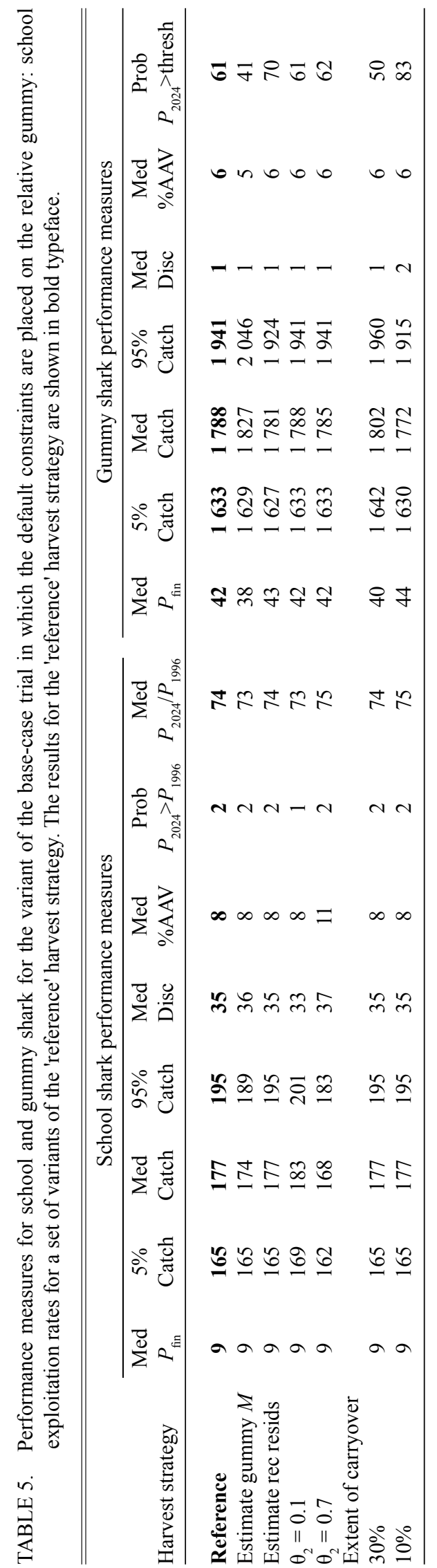

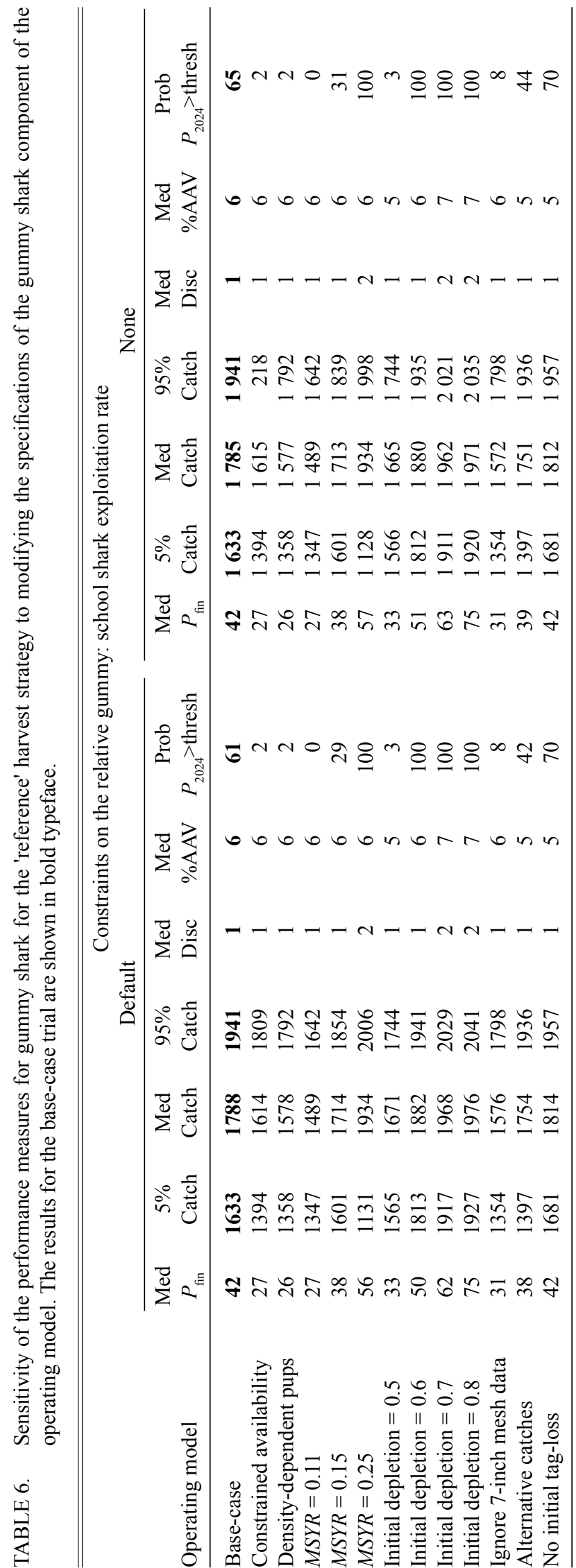


PUNT et al.: Harvest Strategy Evaluation

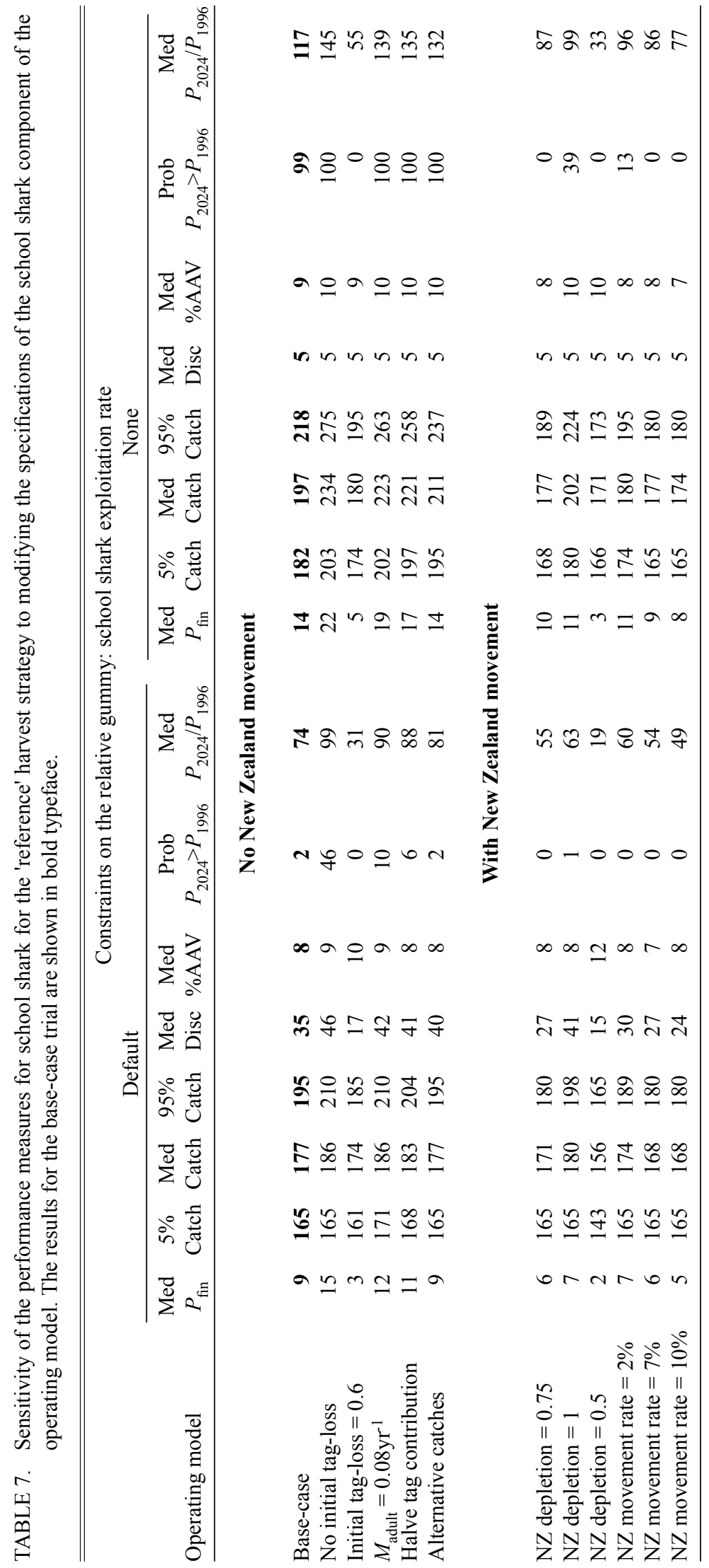



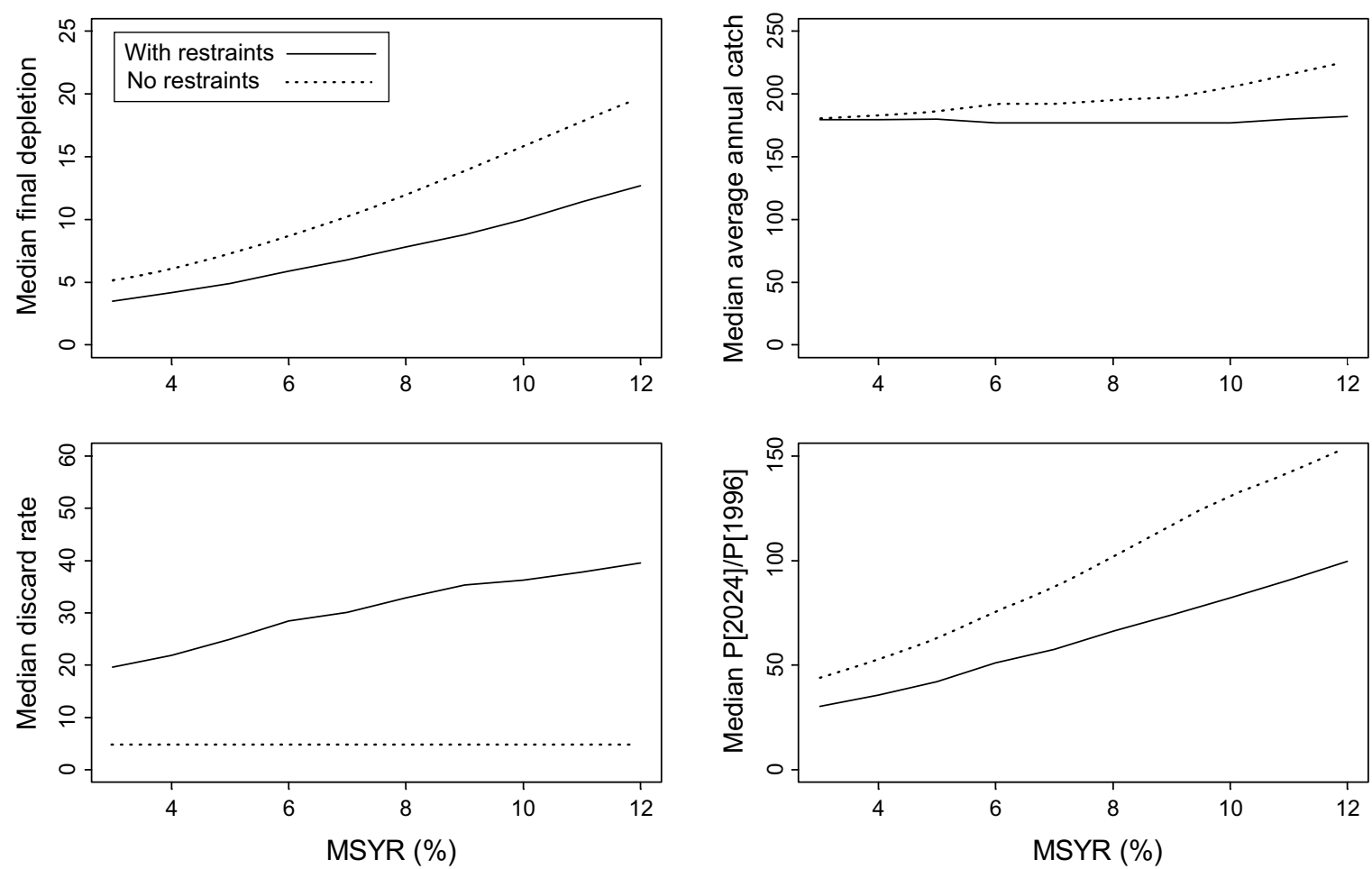

Fig. 4. For school shark, median final depletion, median average annual catch, median discard rate and the median of the ratio of $P_{2024}$ to $P_{1996}$ as a function of the value assumed for MSYR for school shark. Results are shown for the default constraints on the relative school: gummy exploitation rate and for no constraints on this relative exploitation rate.

suggest that it is probably in the range $7-11 \%$ (Punt et al., 2001b).

The sensitivity of the results for school shark to a range of assumptions regarding the constraints placed on the relative gummy: school exploitation rate is examined in Fig. 5. The options "Alt-1" and "Alt-2" in Fig. 5 are intermediate between the "default" constraints and ignoring any TAC-related discarding, and involve linearly interpolating the exploitation rate constraints between the default values and none. The option "No discarding" in Fig. 5 ignores all sources of discarding (i.e. no TACrelated discarding and no high-grading or additional damage-related discarding). As expected, performance in terms of allowing recovery of the school shark resource (and, in fact, in terms of the catches of school shark) improves as the extent of discarding due to mis-matches in TACs is reduced.

\section{Sensitivity to the data used when setting TACs}

Table 8 examines the sensitivity of the performance measures to changing the data available for TAC setting. Ignoring the length-frequency data leads to lower average annual catches of gummy shark. Ignoring the agecomposition data leads to higher average annual catches of gummy shark, but there is less than a $50 \%$ chance that the number of gummy sharks will exceed the lower of $40 \%$ of the virgin level and the 1994 level (see the statistic ' $P_{2024}>$ thresh' in row 'No age-composition data' of Table $8)$. The results are not very sensitive to halving or doubling the survey sample size $\left(N_{2}\right)$; catches of gummy shark are, however, slightly higher if the sample sizes are doubled for the "default constraints" case (row "Double survey sample size" in Table 8).

Including the CPUE data (along with the survey, length-frequency and age-composition data) in the assessment leads to markedly lower catches of gummy shark and consequently better recovery of school shark (Table 8). Basing the assessments solely on the CPUE data leads to lower but more variable landed catches of school shark, increased discarding of school shark, and a lower probability of gummy shark being above the lower of $40 \%$ of the virgin level and the 1994 level in 2024. As expected, the distribution of average annual gummy shark catches is wider than for the base-case when the harvest strategy uses only CPUE data. 

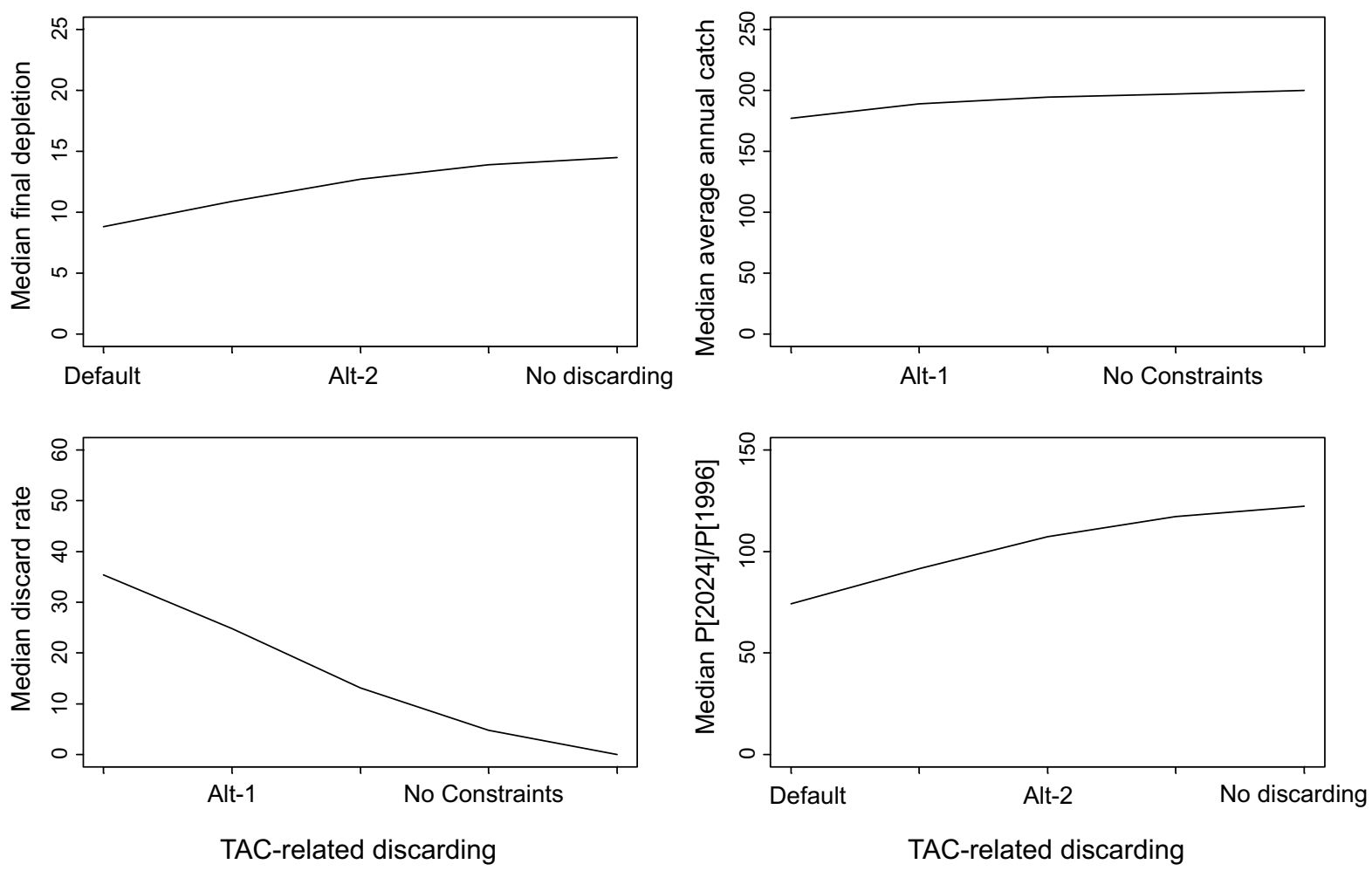

Fig. 5. For school shark, median final depletion, median average annual catch, median discard rate and the median of the ratio of $P_{2024}$ to $P_{1996}$ as a function of assumptions regarding the constraints placed on the relative gummy: school exploitation rate.

\section{General Discussion}

Ultimately, any harvest strategy for school and gummy shark should promote the recovery of the school shark resource without impacting substantially on the catches of gummy shark. The 'reference' harvest strategy examined in Tables 5-8 was chosen because it achieves a 'tolerable' balance between risk and reward. Any such balance is, however, subjective to some extent and, in this case, is simply one chosen by the authors of this paper. Any final decision regarding a harvest strategy will be made by AFMA based on advice from SharkMAC and other relevant advisory bodies.

One outcome from an evaluation of harvest strategies is that the uncertainties that most impact the ability to satisfy the management objectives are identified. In principle, this could be used to prioritize future management-related research (Butterworth and Punt, 1999). As expected from observations of the process of developing harvest strategies in other fishery jurisdictions (Butterworth and Punt, 1999), the results of the application of the Management Strategy Evaluation framework to the problem of setting TACs for school and gummy shark highlight that there are only a few key uncertainties to which candidate harvest strategies are particularly sensitive. For the Southern Shark Fishery these are listed as follows:

a) The extent of future TAC-related discarding. Recovery of school shark pup production to above the level in 1996 depends critically on whether fishers can modify their targeting practices to avoid school shark (e.g. Fig. 5).

b) The value of the MSYR parameter. Although it is not unexpected from previous studies that the values for the performance measures are highly sensitive to the value for the parameter that determines productivity $(M S Y R)$, this is the key uncertainty once an assumption regarding the extent of future TAC-related discarding is made (Fig. 4, Tables 6 and 7).

c) The extent of initial tag-loss/tagging mortality. This factor can have a marked impact on performance, in that final depletions and annual catches are lower when there is initial tag-loss/ tagging mortality (Tables 6 and 7). 
J. Northw. Atl. Fish. Sci., Vol. 35, 2005

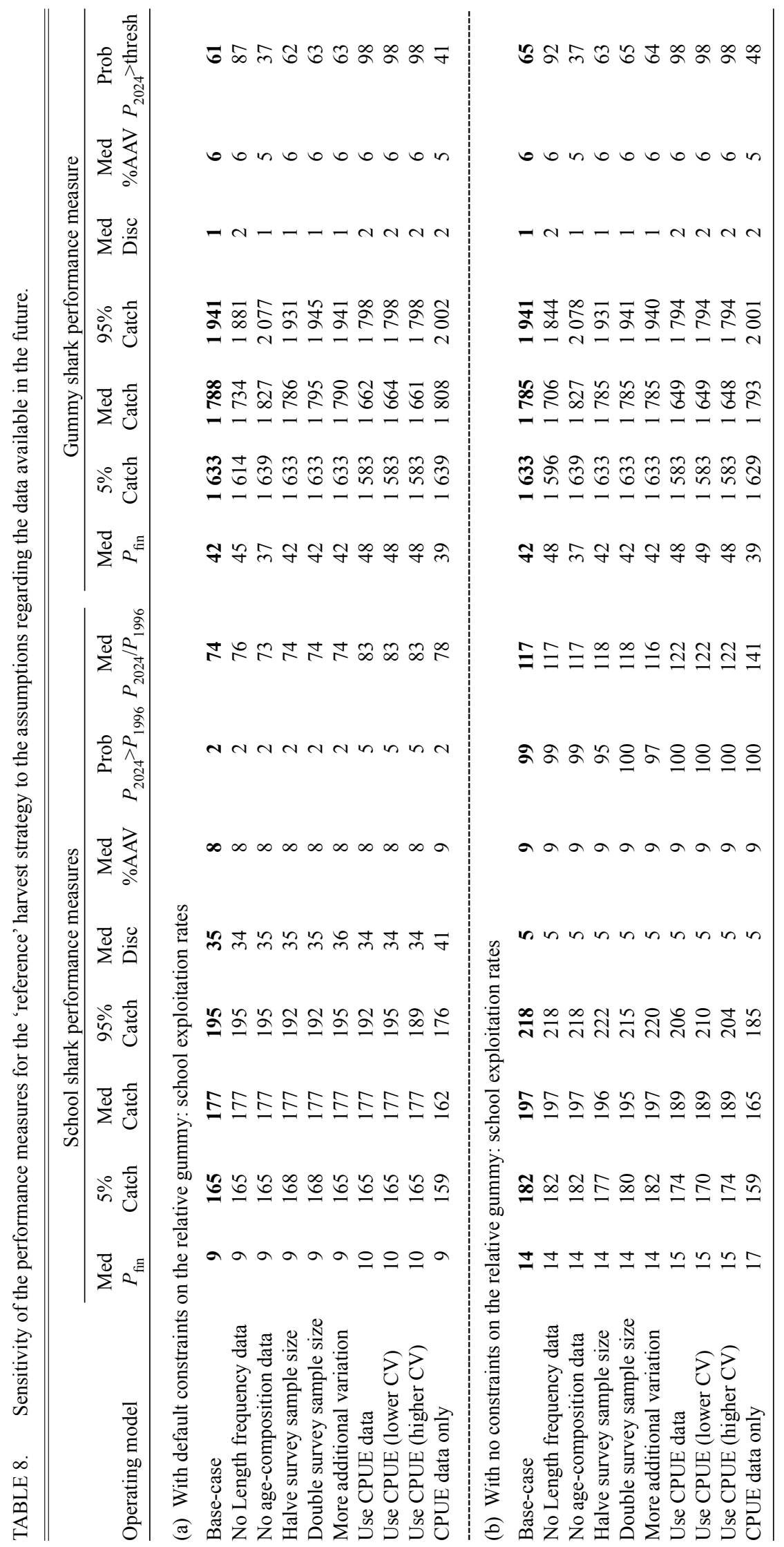


The result that the performances of harvest strategies are highly sensitive to the extent of (technical) interaction between school and gummy shark is perhaps intuitive. Nevertheless, shark species are commonly bycatch or by-product species. The results presented in this paper indicate that ignoring technical interactions may severely over-estimate the ability to recover species that are not major target species. Unfortunately, apart from a few notable exceptions (anchovy and pilchard off South Africa (e.g. Cochrane et al., 1998; Geromont et al., 1999) and species in Australia's South East Fishery (e.g. Punt et al., 2002)), evaluations of harvest strategies have ignored technical interactions.

None of the harvest strategies considered in this paper performed well at allowing the school shark resource to recover in the short term. This is partly because of the poor status of the resource and the relatively low productivity of school shark but also because of the technical interaction between school and gummy shark. In order to achieve a higher probability of recovery, the constraints suggested by SharkMAC, such as minimum TAC levels and maximum inter-annual percentage changes in TAC, will need revision. If fishers are unable (or unwilling) to modify their targeting practices to avoid TAC-related discarding of school shark, it may be necessary to reduce the catches of gummy shark to lower levels than would be appropriate if gummy shark was the target of a single species fishery.

\section{Acknowledgements}

Funding for this work was provided by the Fisheries Research and Development Corporation (FRDC) through FRDC grant 99/102 and by the Australian Fisheries Management Authority. The remaining members of SharkFAG are thanked for their suggestions regarding the hypotheses to include in the operating models. Russell Hudson and Lauren Brown (MAFRI) are thanked for collecting and managing the data. Robin Thomson and two anonymous reviewers are thanked for their comments on an earlier version of this paper.

\section{References}

ANON. 1998. AFMA Annual Report 1997-98. Australian Fisheries Management Authority, Canberra.

BUTTERWORTH, D. S. 1987. A suggested amendment to the harvesting strategy used at ICSEAF to specify hake TAC levels Col. Vol. Sci. Pap. ICSEAF, 14: 101-108.

BUTTERWORTH, D. S., and A. E. PUNT. 1999. Experiences in the evaluation and implementation of management procedures. ICES J. Mar. Sci., 56: 985-998.

BUTTERWORTH, D. S., K. L. COCHRANE, and J. A. A. DE OLIVEIRA. 1997. Management procedures: A better way to manage fisheries? The South African experience. In: Global Trends: Fisheries Management. E. Pikitch,
D. D. Huppert, and M. P. Sissenwine (eds.), p. 83-90.

COCHRANE, K. L., D. S. BUTTERWORTH, J. A. A. DE OLIVEIRA, and B. A. ROEL. 1998. Management procedures in a fishery based on highly variable stocks and with conflicting objectives: Experiences in the South African pelagic fishery. Rev. Fish. Biol. Fish., 8: 177-214.

DONOVAN, G. P. 1989. The Comprehensive Assessment of Whale Stocks: The Early Years. Rep. Int., Whal. Comm. (Special Issue 11).

FAO. 1995. Precautionary approach to fisheries. Part 1: Guidelines on the precautionary approach to capture fisheries and species introductions. FAO Fish. Tech. Pap., 350/1.

GEROMONT, H. F., J. A. A. DE OLIVEIRA, S. J. JOHNSON, and C. L. CUNNINGHAM. 1999. Development and application of management procedures for fisheries in southern Africa. ICES J. Mar. Sci., 56: 952-966.

HILBORN, R. 1979. Comparison of fisheries control systems that utilize catch and effort data. J. Fish. Res. Board Can., 36: $1477-1489$.

HURST, R. J., N. W. BAGLEY, G. A. MCGREGOR, and M. P. FRANCIS. 1999. Movements of the New Zealand school shark, Galeorhinus galeus, from tag returns. NZ J. Mar. Freshw. Res., 33: 29-48.

KAUFMANN, B., G. GEEN, and S. SEN. 1999. Fish Futures: Individual Transferable Quotas in Fisheries. Fisheries Economics, Research and Management Pty Ltd., Kiama.

LUDWIG, D., R. HILBORN, and C. WALTERS. 1993. Uncertainty, resource exploitation, and conservation: Lessons from history. Nature, 260: (2 April), p. 17+36.

MCALLISTER, M. K., and J. N. IANELLI. 1997. Bayesian stock assessment using catch-age data and the sampling - importance resampling algorithm. Can. J. Fish. Aquat. Sci., 54: 284-300.

MCALLISTER, M. K., P. J. STARR, V. R. RESTREPO, and G. P. KIRKWOOD. 1999. Formulating quantitative methods to evaluate fishery-management systems: what fishery processes should be modelled and what trade-offs should be made? ICES J. Mar. Sci., 56: 900-916.

MCLOUGHLIN, K., T. WALKER, and A. PUNT. 2000. Southern Shark Fishery. In: Fishery Status Reports 1999: Resource Assessments of Australian Commonwealth Fisheries. A. Caton, and K. Mcloughlin (eds.), p. 143-150.

METHOT, R. D. 1989. Synthetic estimates of historical abundance and mortality for northern anchovy. AFS Symp., 6: $66-82$.

1990. Synthesis model: an adaptable framework for analysis of diverse stock assessment data. Bull. Int. North Pac. Fish. Commn, 50: 259-277.

POPE, J. G. and J. G. SHEPHERD. 1985. A comparison of the performance of various methods for tuning VPAs using effort data. J. Cons. int. Explor. Mer., 42: 129-151.

PRIBAC, F., A. E. PUNT, T. I. WALKER, and B. L. TAYLOR. 2004. Using Length, Age and Tagging Data in a Stock Assessment of a Length Selective Fishery for Gummy Shark (Mustelus antarcticus). J. Northw. Atl. Fish. Sci., 35: 267-290 (this volume).

PRINCE, J., L. BROWN, and T. WALKER. 1999. Pilot fisheryindependent fixed-station survey for southern shark stocks. Final Report to the Australian Fisheries Management 
Authority. Australian Fisheries Management Authority, Canberra.

PUNT, A. E. 1994. Assessments of the stocks of Cape hake Merluccius spp. off South Africa. S. Afr. J. Mar. Sci., 14: 159-186.

PUNT, A. E., and D. S. BUTTERWORTH. 1989. Results of first stage screening trials for a proposed whale stock management procedure. Rep. Int. Whal. Comm. (Special Issue 11): 191-197.

1993. Variance estimates for fisheries assessment: their importance and how best to evaluate them. In: Risk Evaluation and Biological Reference Points for Fisheries Management. S. J. Smith, J. J. Hunt and D. Rivard (eds.), Spec. Publ. Can. J. Fish. Aquat. Sci, 120: 145-162.

PUNT, A. E., and R. B. KENNEDY 1997. Population modelling of Tasmanian rock lobster, Jasus edwardsii, resources. Mar. Freshw. Res., 48: 967-980.

PUNT, A. E., F. PRIBAC, T. I. WALKER, B. L. TAYLOR, and J. D. PRINCE. 2000. Stock assessment of school shark Galeorhinus galeus based on a spatially-explicit population dynamics model. Mar. Freshw. Res., 51: 205-220.

2001b. Population modelling and harvest strategy evaluation for school and gummy shark. Report of FRDC 99/102. CSIRO Marine Research, Hobart.

PUNT, A. E., A. D. M. SMITH, and G. CUI. 2001a. Review of progress in the introduction of management strategy evaluation (MSE) approaches in Australia's South East Fishery. Mar. Freshw. Res., 52: 719-726.

2002. Evaluation of management tools for Australia's South East Fishery. 3. Towards selecting appropriate harvest strategies. Mar. Freshw. Res., 53: 645-660.

PUNT, A. E., T. I. WALKER, and J. D. PRINCE. 2001c. Assessing the management-related benefits of fixed-station fishery-independent surveys in Australia's southern shark fishery. Fisheries Research, 55: 281-295.

SMITH, A. D. M. 1994. Management Strategy Evaluation - The Light on the Hill. In: Population Dynamics for
Fisheries Management, Australian Society for Fish Biology Workshop Proceedings, Perth 24-25 August 1993. D. A. Hancock (ed.), p. 249-253.

SMITH, A. D. M., K. J. SAINSBURY, and R. A. STEVENS. 1999. Implementing effective fisheries-management systems - management strategy evaluation and the Australian partnership approach. ICES J. Mar. Sci., 56: $967-979$.

SOUTHWARD, G. M. 1968. A simulation of management strategies in the Pacific Halibut fishery. Int. Pac. Halibut Commn Rep., 47: 1-70.

STARR, P. J., P. A. BREEN, R. HILBORN, and T. H. KENDRICK. 1997. Evaluation of a management decision rule for a New Zealand rock lobster substock. Mar. Freshw. Res., 48: 1093-1101.

WALKER, T. I. 1994a. Fishery model of gummy shark, Mustelus antarcticus, for Bass Strait. In: Resource Technology '94 New Opportunities Best Practice, The Centre for Geographic Information Systems \& Modelling. I. Bishop (ed.), p. 422-438.

1994b. Stock assessments of the gummy shark, Mustelus antarcticus Günther, in Bass Strait and off South Australia. In: Population Dynamics for Fisheries Management, Australian Society for Fish Biology Workshop Proceedings, Perth 24-25 August 1993. D. A. Hancock (ed.), p. 173-187.

1999. Southern Australian shark fishery management. In: Case Studies of Management of Elasmobranch Fisheries. R. Shotton (ed.), FAO Fish. Tech. Pap., 378/2: 480-514.

WALKER, T. I., D. JOHNSON, D. BROWN, and K. MCLOUGHLIN. (eds.) 1998. The Southern Shark Fishery 1997, Fishery Assessment Report, Southern Shark Fishery Assessment Group, Australian Fisheries Management Authority, Canberra.

WALTERS, C. J., and P. H. PEARSE 1996. Stock information requirements for quota management systems in commercial fisheries. Rev. Fish. Biol. Fish., 6: 21-42. 